\title{
Mesoscale and high-frequency variability in the Ross Sea (Antarctica): An introduction to the special issue
}

\author{
Dennis J. McGillicuddy, Jr. ${ }^{a}$ \\ Giorgio Budillon ${ }^{\mathrm{b}}$ \\ Adam Kustka $^{\mathrm{c}}$ \\ Manuscript in preparation for Journal of Marine Systems
}

October 15, 2016

${ }^{a}$ Department of Applied Ocean Physics and Engineering, Woods Hole Oceanographic Institution, Woods Hole, MA 02543, USA. Tel: 508-289-2683 Fax: 508-457-2194 Email:

dmcgillicuddy@whoi.edu (Corresponding Author).

${ }^{b}$ University of Naples "Parthenope" Department of Science and Technology, Centro Direzionale - Isola C4, 80143 Napoli - Italy. Email: giorgio.budillon@ uniparthenope.it

${ }^{c}$ Department of Earth \& Environmental Sciences, Rutgers, The State University of New Jersey, 101 Warren Street, Smith Hall Room 140, Newark, New Jersey 07102, USA. Email: kustka@andromeda.rutgers.edu 
Variability on short temporal and small spatial scales poses particularly difficult challenges to the field of oceanography. To begin with, these high frequency and high wavenumber fluctuations can confound interpretation of longer-term trends in mean properties of the physical, biological, and chemical characteristics of the ocean. This "noise" superimposed on the trends of interest must be filtered out to obtain accurate estimates of such temporal changes (seasonal, annual, interannual, interdecadal, etc.). Secondly, such fluctuations can actually contribute to the mean properties themselves. For example, mesoscale eddies contribute significantly to the general circulation in a number of areas throughout the world ocean (McWilliams, 2008). A classic construct for separation of the mean field $\bar{\varphi}_{l}$ and its variability $\varphi_{i}^{\prime}$ is provided by the Reynolds decomposition, in which the fluctuating component averages to zero: $\varphi_{i}=\bar{\varphi}_{\imath}+\varphi_{i}^{\prime}$. The Reynolds average of the product of two constituents $\overline{\varphi_{l} \varphi_{j}}$ includes contributions not only from the means $\overline{\varphi_{i}} \overline{\varphi_{j}}$ but also from the Reynolds stresses $\overline{\varphi_{l}^{\prime} \varphi_{j}^{\prime}}$, the latter of which represents the net effect of the fluctuating components. Yet another impact of variability on mean properties stems from the fact that biological and chemical transformations typically involve nonlinear functions; even though $\overline{\varphi_{l}^{\prime}}=0$, the average value of such a function operating on the fluctuations $\overline{f\left(\varphi_{l}^{\prime}\right)}$ can be significantly different from zero. For all of these reasons, it is of considerable interest to characterize the variability of the ocean over the full spectra on which such fluctuations exist. However, given the difficulty and expense of making in situ measurements in the ocean, high frequency and high wavenumber variability tend to be chronically undersampled.

This statement is particularly true in remote areas of the world ocean, such as the Ross Sea (Fig. 1a). One notable exception is the study of Hales and Takahashi (2004), which used the Lamont Pumping SeaSoar to sample physical, bio-optical and biogeochemical properties of the upper $100 \mathrm{~m}$ at a horizontal resolution of $3-5 \mathrm{~km}$. They observed significant variability at length scales on the order of $10 \mathrm{~km}$ or less in nearly all the quantities measured. Indeed, satellite ocean color imagery in the Ross Sea is suggestive of an energetic mesoscale (Fig. 1b). However, the mechanisms generating this patchiness in the Ross Sea are not known. Likely candidates include advective stirring and local stimulation of productivity via iron supply and/or light availability through variations in mixed layer depth. Cross-shelf transport of Modified Circumpolar Deep Water (MCDW) could be involved in both aspects, as well as the larger-scale penetration of lowbiomass water from offshore that is apparently constrained to the troughs adjacent to Pennell and Mawson Banks (Reddy and Arrigo, 2006).

The need to understand the mechanisms responsible for such mesoscale and highfrequency phenomena in the Ross Sea is motivated by the important physical, biological, and biogeochemical processes that take place there. Not only is the Ross Sea a site of bottom water formation (Gordon et al., 2009; Jacobs and Giulivi, 1999), it is the single most productive area in the Southern Ocean (Smith et al., 2014a) and may constitute a significant but unaccounted for oceanic sink of atmospheric carbon dioxide, largely driven by phytoplankton production (Arrigo et al., 2008). Recent field efforts aimed at various aspects of these problems have paid special attention to resolving mesoscale eddies and other high frequency variability. This issue is an initial attempt to synthesize findings from "Processes Regulating Iron Supply at the Mesoscale" (PRISM ${ }^{1}$; McGillicuddy et al., 2015), "Slocum Enhanced Adaptive Fe Algal Research in the

\footnotetext{
${ }^{1}$ http://science.whoi.edu/users/olga/PRISM_RS/PRISM_RS.html
} 
Ross Sea" (SEAFAReRS; Smith et al., 2014), the "Ross Sea Mesoscale Experiment" (RoME; Rivaro et al., this issue; Misic et al., this issue) and several national Italian programs.

Many aspects of the striking seasonal variability in the Ross Sea stem from the polynyas characteristic of the region. Although these polynyas are a seasonal phenomenon, their dynamics are strongly influenced by high-frequency and small-scale variations in wind forcing (Sansiviero et al., this issue). By incorporating these aspects into an advanced numerical model, Sansiviero et al. are able to achieve realistic hindcasts of the Terra Nova Bay polynya. Dynamics of these ice masses are critical to the phytoplankton living within them (Saggiomo et al., this issue), which are important not only locally but also in seeding open water blooms.

Seasonal variability is also present in the inflow of MCDW onto the Ross Sea continental shelf, as revealed by a ten-year time-series of moored observations described by Castagno et al. (this issue). These data also document fluctuations on a wide range of time scales, from tidal to interannual. Complementary hydrographic sections illustrate how MCDW inflows are constrained by the topography to enter through deep troughs between the various banks along the outer continental shelf. The impact of MCDW-derived dissolved iron on fueling phytoplankton blooms on Pennell and Mawson Banks is examined in Kustka et al. (2015) as well as two additional papers in this issue (Kohut et al.; Hatta et al.). Kustka et al. found MCDW to be less important than benthic sources in sustaining phytoplankton on Pennell Bank. Comparisons of Pennell and Mawson Banks by Kohut et al. and Hatta et al. reach the same conclusion with respect to the relative importance of benthic and MCDW sources of dissolved iron. However, they differ somewhat in their explanations for why phytoplankton concentrations are higher on Pennell than Mawson Bank. Whereas both studies indicate a stronger density gradient above the bottom mixed layer on Mawson Bank inhibiting delivery of the benthic source to surface waters, Kohut et al. suggest two additional factors: (1) a weaker sedimentary source of iron on Mawson Bank due to more scouring by stronger tidal currents, and (2) longer residence times of surface waters on Pennell Bank favoring retention of phytoplankton blooms.

The processes involved in iron supply are addressed in Mack et al. (this issue), who diagnose transport pathways and flux estimates from a realistic circulation model of the region. Tracer simulations explicitly represent sources from the benthos and MCDW as described above, as well as sources from melting sea ice and glacial input. Although their results are somewhat sensitive to tidal forcing and horizontal grid resolution, benthic sources generally provide the largest input of iron on a regional basis, consistent with other recent studies (Gerringa et al., 2015; Marsay et al., 2014; McGillicuddy et al., 2015). The next largest sources of iron are sea ice melt and MCDW, with a very modest input from glacial sources. Ryan-Keogh et al. (this issue) examine the biological consequences of variations iron supply, describing seasonal changes toward an iron-efficient photosynthetic strategy that may contribute to a shift in the phytoplankton assemblage from one comprised mostly of Phaeocystis antarctica to one dominated by diatoms as iron becomes limiting.

Within the context of such seasonal variations, there are mesoscale fluctuations whose amplitude in some cases can approach that of the seasonal variability itself. For example, Smith et al. (this issue) use optical measurements from the Video Plankton Recorder to document dramatic fluctuations in $P$. antarctica associated with fronts and eddies in various regimes within the Ross Sea. One such regime occurs along the edge of the Ross Ice Shelf, where eddies of 20$30 \mathrm{~km}$ in diameter containing the cold and fresh signature of glacial meltwater are generated by an instability process enhanced by roughness along the edge of the ice shelf ( $\mathrm{Li}$ et al., this issue). Bochdansky et al. (this issue) describe measurements using both an in situ digital holographic 
microscope and a video particle profiler that reveal small-scale and mesoscale patterns in particle abundance, composition, and export. Vertical resolution of $<1 \mathrm{~m}$ facilitates characterization of fine-scale patchiness that correlates with density structure, thereby indicative of physicalbiological interactions in shaping the observed distributions. Misic et al. (this issue) also document mesoscale fluctuations in distribution of particulate organic matter, with substantial variations in its lability that may regulate its utilization by higher trophic levels and export to depth. High-resolution spatial surveys of the carbonate system (Rivaro et al., this issue) indicate variability on scales of $10 \mathrm{~km}$, driven primarily by mesoscale perturbations to phytoplankton activity. The imprint of mesoscale physical-biological interactions is also detected in higher trophic levels, as acoustic surveys of krill reveal negative correlations between Euphausia superba and salinity, whereas E. crystallorophias is positively correlated with fluorescence. Acoustic time-series data are suggestive of event-driven changes in the abundance of migrating zooplankton, although much of the variance in the year-long record occurred at diel and tidal frequencies (Picco et al., this issue).

Study of high-frequency and small-scale variations in the ocean is facilitated by the use of autonomous observing platforms such as gliders, whose use is becoming more common in regional studies. In situations where oceanographic features of interest are relatively stationary, as is the case when they are associated with bottom topography, glider sections can be an effective means to characterize them. For example, Kustka et al. (2015) and Kohut et al. (this issue) use glider sections to map phytoplankton blooms overlying Mawson and Pennell Banks. Jones and Smith (this issue) utilize a different sampling approach, using the glider for long-term occupation of a $25 \times 50 \mathrm{~km}$ grid in time-series mode. Although spatial variability is present in the data, the repeat occupations in this survey area permit effective extraction of high-frequency temporal variability in chlorophyll fluorescence, which are driven primarily by wind-driven mixing. Such short-term events are severely undersampled by typical shipboard measurements, and may play an important role in biogeochemical cycling.

The studies described herein constitute an initial step toward characterization of high frequency and mesoscale variability in the Ross Sea. Although these findings are substantial, considerably more effort will be needed to fully characterize the wide variety of processes involved. Fortunately, future progress in this area will be facilitated by continuous improvement in observing technologies and their use not only on ships but also on autonomous platforms. Models of increasing spatial and temporal resolution will play an important role in interpreting these observations and ultimately understanding the impacts of mesoscale and high frequency variability in mean properties and fluxes of physical, biological, and chemical materials.

\section{Acknowledgments}

Support of this research by the National Science Foundation's United States Antarctic Program and the Italian National Antarctic Research Program (PNRA) is gratefully acknowledged. We thank the officers, crew, and technical personnel on board the R/V Nathaniel B. Palmer and R/V Italica for their outstanding support during seagoing operations. Additional support by the National Aeronautics and Space Administration is greatly appreciated.

Italian researchers fondly remember their friend and colleague Luigi Michaud, who tragically died January 17th 2014 in the Ross Sea that he loved and studied with great passion. 


\section{References}

Arrigo, K.R., van Dijken, G., Long, M., 2008. Coastal Southern Ocean: A strong anthropogenic $\mathrm{CO}_{2}$ sink. Geophysical Research Letters 35, doi:10.1029/2008GL035624.

Bochdansky, A.B., Clouse, M.A., Hansell, D.A., this issue. Mesoscale and high-frequency variability of macroscopic particles $(>100 \mu \mathrm{m})$ in the Ross Sea and its relevance for late-season particulate carbon export. Journal of Marine Systems.

Castagno, P., Falco, P., Dinniman, M.S., Spezie, G., Budillon, G., this issue. Temporal variability of the Circumpolar Deep Water inflow onto the Ross Sea continental shelf. Journal of Marine Systems.

Gerringa, L.J.A., Laan, P., van Dijken, G.L., van Haren, H., De Baar, H.J.W., Arrigo, K.R., Alderkamp, A.C., 2015. Sources of iron in the Ross Sea polynya in early summer. Marine Chemistry 177, 447-459.

Gordon, A.L., Padman, L., Bergamasco, A., 2009. Southern Ocean shelf slope exchange. Deep Sea Research Part II: Topical Studies in Oceanography 56, 775-777.

Hales, B., Takahashi, T., 2004. High-resolution biogeochemical investigation of the Ross Sea, Antarctica, during the AESOPS (US JGOFS) program. Global Biogeochemical Cycles 18, doi:10.1029/2003GB002165.

Hatta, M., Measures, C.I., Lam, P.J., Ohnemus, D.C., Auro, M.E., Grand, M.M., Selph, K.E., this issue. The relative roles of modified circumpolar deep water and benthic sources in supplying iron to the recurrent phytoplankton blooms above Pennell and Mawson Banks, Ross Sea, Antarctica. Journal of Marine Systems.

Jacobs, S.S., Giulivi, C.F., 1999. Thermohaline data and ocean circulation on the Ross Sea continental shelf, in: Spezie, G., Manzella, G.M.R. (Eds.), Oceanography of the Ross Sea Antarctica, pp. 3-16.

Jones, R.M., Smith, W.O., this issue. The influence of short-term events on the hydrographic and biological structure of the southwestern Ross Sea. Journal of Marine Systems.

Kohut, J.T., Kustka, A.B., R. Hiscock, M., Lam, P.J., Measures, C., Milligan, A., White, A., Carvalho, F., Hatta, M., Jones, B.M., Ohnemus, D.C., Swartz, J.M., this issue. Mesoscale variability of the summer bloom over the northern Ross Sea shelf: A tale of two banks. Journal of Marine Systems.

Kustka, A.B., Kohut, J.T., White, A.E., Lam, P.J., Milligan, A.J., Dinniman, M.S., Mack, S., Hunter, E., Hiscock, M.R., Smith Jr, W.O., Measures, C.I., 2015. The roles of MCDW and deep water iron supply in sustaining a recurrent phytoplankton bloom on central Pennell Bank (Ross Sea). Deep Sea Research I 105, 171-185. 
Leonori, I., De Felice, A., Canduci, G., Costantini, I., Biagiotti , I., Budillon., G., this issue. Krill distribution in relation to environmental parameters in mesoscale structures in the Ross Sea. Journal of Marine Systems.

Li, Y., McGillicuddy, D.J., Dinniman, M.S., Klinck, J.M., this issue. Processes influencing formation of low-salinity high-biomass lenses near the edge of the Ross Ice Shelf. Journal of Marine Systems.

Mack, S.L., Dinniman, M.S., McGillicuddy, D.J., Sedwick, P.N., Klinck, J.M., this issue. Dissolved iron transport pathways in the Ross Sea: Influence of tides and mesoscale eddies in a regional ocean model. Journal of Marine Systems.

Marsay, C.M., Sedwick, P.N., Dinniman, M.S., Barrett, P.M., Mack, S.L., McGillicuddy, D.J., 2014. Estimating the benthic efflux of dissolved iron on the Ross Sea continental shelf.

Geophysical Research Letters, 2014GL061684.

McGillicuddy, D.J., Sedwick, P.N., Dinniman, M.S., Arrigo, K.R., Bibby, T.S., Greenan, B.J.W., Hofmann, E.E., Klinck, J.M., Smith, W.O., Mack, S.L., Marsay, C.M., Sohst, B.M., van Dijken, G.L., 2015. Iron supply and demand in an Antarctic shelf ecosystem. Geophysical Research Letters 42, 8088-8097.

McWilliams, J.C., 2008. The Nature and Consequences of Oceanic Eddies, Ocean Modeling in an Eddying Regime. American Geophysical Union, pp. 5-15.

Misic, C., Covazzi Harriague, A., Mangoni, O., Aulicino, G., Castagno, P., Cotroneo, Y., this issue. Effects of physical constraints on the lability of POM during summer in the Ross Sea. Journal of Marine Systems.

Mosola, A.B., Anderson, J.B., 2006. Expansion and rapid retreat of the West Antarctic Ice Sheet in eastern Ross Sea: possible consequence of over-extended ice streams? Quaternary Science Reviews 25, 2177-2196.

Picco, P., Schiano, M.E., Pensieri, S., Bozzano, R., this issue. Time-frequency analysis of migrating zooplankton in the Terra Nova Bay polynya (Ross Sea, Antarctica). Journal of Marine Systems.

Reddy, T.E., Arrigo, K.R., 2006. Constraints on the extent of the Ross Sea phytoplankton bloom. Journal of Geophysical Research: Oceans 111, 1-8.

Rivaro, P., Ianni, C., Langone, L., Ori, C., Aulicino, G., Cotroneo, Y., Saggiomo, M., Mangoni, O., this issue. Physical and biological forcing of mesoscale variability in the carbonate system of the Ross Sea (Antarctica) during summer 2014. Journal of Marine Systems.

Ryan-Keogh, T.J., DeLizo, L.M., Smith Jr, W.O., Sedwick, P.N., McGillicuddy Jr, D.J., Moore, C.M., Bibby, T.S., this issue. Temporal progression of photosynthetic-strategy in phytoplankton in the Ross Sea, Antarctica. Journal of Marine Systems. 
Saggiomo, M., Poulin, M., Mangoni, O., Lazzara, L., De Stefano, M., Sarno, D., Zingone, A., this issue. Spring-time dynamics of diatom communities in landfast and underlying platelet ice in Terra Nova Bay, Ross Sea, Antarctica. Journal of Marine Systems.

Sansiviero, M., Morales Maqueda, M.Á., Fusco, G., Aulicino, G., Flocco, D., Budillon, G., this issue. Modelling sea ice formation in the Terra Nova Bay polynya. Journal of Marine Systems.

Smith, W.O., Ainley, D.G., Arrigo, K.R., Dinniman, M.S., 2014a. The Oceanography and Ecology of the Ross Sea. Annual Review of Marine Science 6, 469-487.

Smith, W.O., Goetz, K.T., Kaufman, D.E., Queste, B.Y., Asper, V., Costa, D.P., Dinniman, M.S., Friedrichs, M.A.M., Hofmann, E.E., Heywood, K.J., Klinck, J.M., Kohut, J.T., Lee, C.M., 2014b. Multiplatform, multidisciplinary investigations of the impacts of Modified Circumpolar Deep Water in the Ross Sea, Antarctica. Oceanography 27, 180-185.

Smith, W.O., McGillicuddy, D.J., Olson, E.B., Kosnyrev, V., Peacock, E.E., Sosik, H.M., this issue. Mesoscale variability in intact and ghost colonies of Phaeocystis antarctica in the Ross Sea: Distribution and abundance. Journal of Marine Systems. 


\section{Figure Captions}

Figure 1. Top: Bathymetric map of the Ross Sea shelf (figure modified from Mosola and Anderson, 2006). Bottom: SeaWiFS ocean color image of the Ross Sea, showing phytoplankton blooms in the polynya, 18 December 1998 (image courtesy of the SeaWiFS Project, NASA GSFC). 
Figures

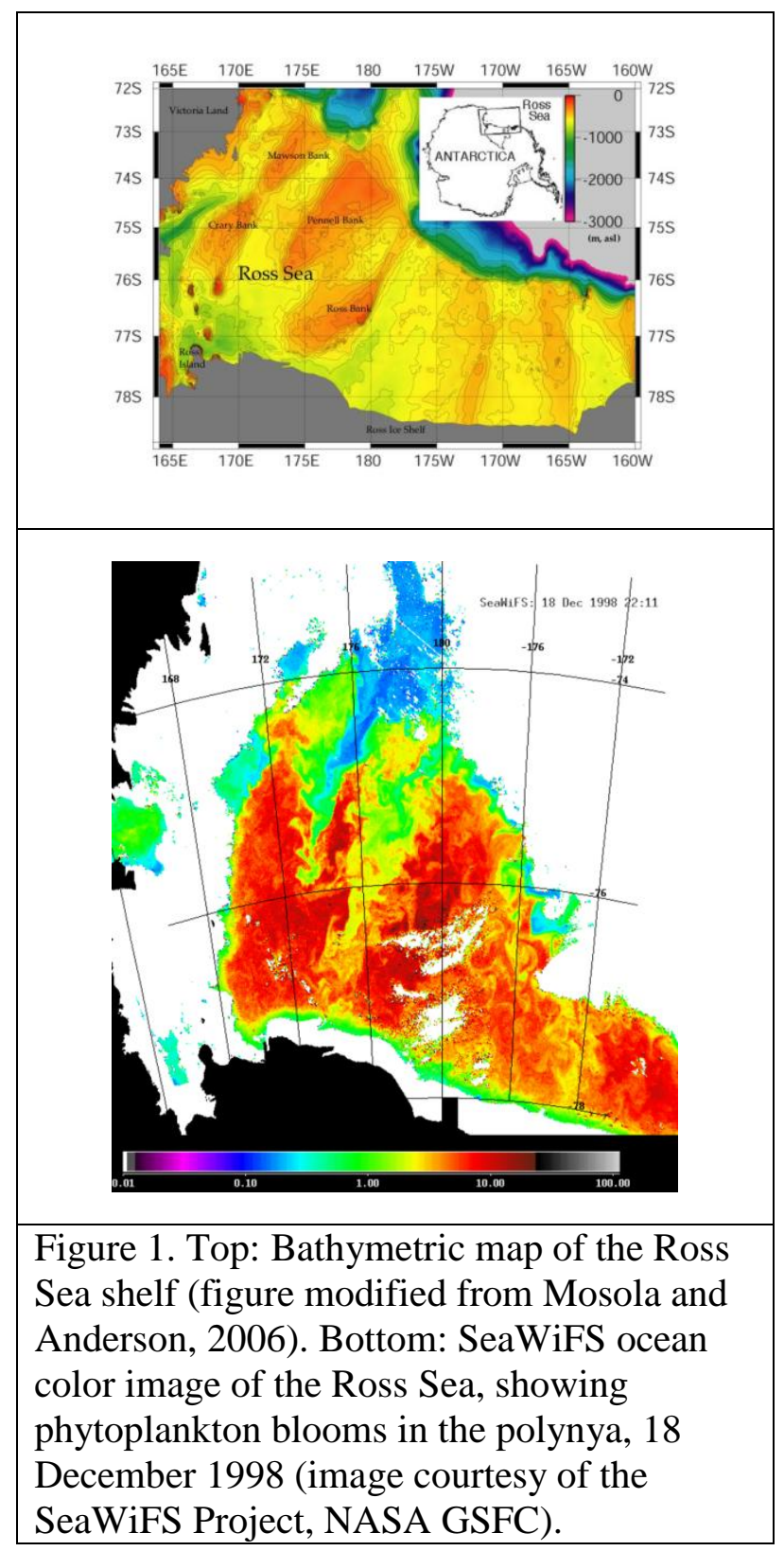

McGillicuddy et al., Figure 1. 